\title{
Effect of fibronectin on HBV infection in primary human fetal hepatocytes in vitro
}

\author{
FANG WANG ${ }^{1}$, XIAOGANG ZHANG ${ }^{2}$, JING ZHANG $^{1}$, LING HUI $^{3}$, YUMING WANG $^{4}$ and XIAOHONG WANG ${ }^{4}$ \\ ${ }^{1}$ Department of Infectious Diseases, Anning Branch of Lanzhou General Hospital, Lanzhou Military Area Command, \\ Lanzhou; ${ }^{2}$ Department of Orthopaedics, Hospital of Traditional Herb in Gansu, Lanzhou; ${ }^{3}$ Experimental Center of Medicine, \\ Lanzhou General Hospital, Lanzhou Military Area Command, Lanzhou; ${ }^{4}$ Department of Infectious Diseases, \\ Southwest Hospital, Third Military Medical University, Chongqing, P.R. China
}

Received March 13, 2012; Accepted July 20, 2012

DOI: $10.3892 / \mathrm{mmr} .2012 .1029$

\begin{abstract}
This study was carried out to investigate the effect of fibronectin (FN) on primary cultured human fetal hepatocytes infected by hepatitis B virus (HBV) in vitro. Human fetal hepatocytes infected by HBV were cultured on culture dishes coated with $\mathrm{FN}$ in vitro. $\mathrm{HBsAg}$ and $\mathrm{HBeAg}$ in supernatants were detected by ELISA, HBcAg in nuclei by immunohistochemistry, HBV DNA by fluorescent quantitative PCR and covalently closed circular DNA (cccDNA) by nested PCR. The results were compared with cells cultured on dishes that were not coated with FN. Positivity for HBsAg and HBeAg in supernatants appeared from day 5 on the non-coated dishes, while positivity for $\mathrm{HBs} \mathrm{Ag}$ and $\mathrm{HBeAg}$ appeared from day 1 on the coated dishes. Positivity for $\mathrm{HBcAg}$ in the nuclei on the non-coated dishes was displayed from day 2 with a positive rate of $15 \%$, while positivity for $\mathrm{HBcAg}$ on the coated dishes was displayed from day 1 with a positive rate of $>90 \%$. HBV DNA in cells on the non-coated dishes was detected from day 4, while that on the coated dishes was detected from day 1. The non-coated dishes were positive for cccDNA from day 8 , while the coated dishes were positive from day 2 . FN coating is capable of accelerating HBV infection in primary cultured fetal hepatocytes in vitro, increasing the duration of $\mathrm{HBV}$ infection and the number of infected cells.
\end{abstract}

\section{Introduction}

Fibronectin (FN), also named fibrinogenase, is an extracellular macromolecular non-collagenous glycoprotein. $\mathrm{FN}$ is mainly produced by hepatocytes, Kupffer cells and endotheliocytes, and is present extensively in cell surfaces, extracellular fluid,

Correspondence to: Professor Ling Hui, Experimental Center of Medicine, Lanzhou General Hospital, Lanzhou Military Area Command, Lanzhou 730050, P.R. China

E-mail: kaixin919@163.com

Key words: fibronectin, hepatitis B virus, HBV infection, human fetal hepatocytes, cell culture connective tissues and the majority of basilar membranes. FN has multiple biological functions. It is capable of promoting blood coagulation, enhancing the reticuloendothelial system and promoting repair in trauma and embryonic formation and development; its correlations with cell transformation and tumor genesis, development, invasion and metastasis have obtained widespread attention. In addition, FN has an impact on such biological behaviors as cellular adhesion, migration, growth, differentiation and diffusion (1). According to the literature, FN in human hepatic blood sinusoids is capable of promoting the uptake of hepatitis B viruses (HBV) by hepatocytes (2). However, to the best of our knowledge, no study on the effect of FN on in vitro-cultured human fetal hepatocytes infected by HBV has been published to date.

In this study, the effect of FN on human fetal hepatocytes infected by HBV was investigated, and is expected to provide a basis for further exploration into the mechanism of hepatocellular HBV infection.

\section{Materials and methods}

Human fetal hepatocytes. A liver from a 22-week fetus aborted artificially was obtained, and the mother was tested as negative for HBsAg. Total liver cell suspension was isolated according to a two-step perfusion method designed by Wang et al (3). Hepatic tissues were placed on a culture dish, and perfused vascularly using $37^{\circ} \mathrm{C}$ perfusate containing $\mathrm{Ca}^{2+}$ and $\mathrm{Mg}^{2+}$ until the majority of the liver appeared gray. The tissues were repeatedly infused with $0.05 \%$ collagenase at $37^{\circ} \mathrm{C}$ (containing $0.1 \%$ dispase), cut up, agitated at $37^{\circ} \mathrm{C}$, digested for $30 \mathrm{~min}$ and then filtered with 3-ply aseptic gauze. Collagenase ( $0.05 \%$; containing $0.1 \%$ dispase) was repeatedly injected into the blood vessel at $37^{\circ} \mathrm{C}$, liver tissues were cut into sections, shocked, digested for $30 \mathrm{~min}$, filtered with 3 layers of sterile gauze, centrifuged at $50 \mathrm{x}$ g for $3 \mathrm{~min}$ three times and liver cells were purified. The cells were cultured with DMEM containing $10 \%$ FBS. The cell concentration was adjusted to $2 \times 10^{5} / \mathrm{ml}$. The cells were then inoculated onto 6-well culture dishes with and without FN coating, with $2 \mathrm{ml}$ of culture solution in each well ( $4 \times 10^{5}$ cells/well). HEPES, $100 \mathrm{U} / \mathrm{ml}$ penicillin and $100 \mu \mathrm{g} / \mathrm{ml}$ streptomycin were added and then incubated in an atmosphere of $5 \% \mathrm{CO}_{2}$ at $37^{\circ} \mathrm{C}$. The culture solution 
was changed $24 \mathrm{~h}$ later. Purified $(100 \mu \mathrm{l})$ serum from patients positive for HBV DNA was added into each well with a quantity ratio between cells and viruses of 1:10. The mixture was incubated at $37^{\circ} \mathrm{C}$ for $16 \mathrm{~h}$ (overnight) and then the supernatant was discarded. Cells were washed six times with PBS (pH 7.4) (the washing mixture from the sixth wash was retained for detection). The cells were continuously cultured with DMEM medium containing $10 \%$ FBS. The day of washing was day 0 after infection, and HBsAg, HBeAg and HBV DNA in supernatants were detected every $24 \mathrm{~h}$ following infection. Two wells of cells with and without FN coating, respectively, were digested and collected with digestive fluid containing $0.05 \%$ trypsin and $0.03 \%$ EDTA every $24 \mathrm{~h}$ from day $1-10$ after infection, in which one well was used for immunohistochemistry following fixation with paraformaldehyde and the other was stored at $-70^{\circ} \mathrm{C}$ for the extraction of DNA. The cells without infected serum were used as a control. Cell survival rates were determined using the trypan blue staining method. This study was conducted in accordance with the declaration of Helsinki and with approval from the Ethics Committee of Southwest Hospital, Third Military Medical University. Written informed consent was obtained from all participants.

FN coating of culture dishes. Aseptic double-distilled water $(5 \mathrm{ml})$ was added into $5 \mathrm{mg} \mathrm{FN}$, then the solution was left to dissolve. Two hundred microliters of the solution was extracted, followed by the addition of $800 \mu \mathrm{l}$ Hanks' buffer salt solution, and then the sample was mixed vigorously. Culture dishes were coated at $2 \mu \mathrm{g} / \mathrm{cm}^{2}$. FN was well spread on the culture dishes with a sterile rubber brush, stored for $4 \mathrm{~h}$ at $37^{\circ} \mathrm{C}$ and then washed three times with culture medium.

Serum infected by $H B V$ and its purification. Serum infected by $\mathrm{HBV}$ was obtained from patients with chronic hepatitis $\mathrm{B}$ in the Department of Infectious Diseases, Anning Branch of Lanzhou General Hospital, Lanzhou Military Area Command. In these patients, HBsAg (+), HBeAg (+) and anti-HBc (+) were detected by ELISA, $5 \times 10^{8}$ copies/ml of HBV DNA was detected by fluorescent quantitative PCR, and negative results were found for hepatitis A, C, D, E and G virus detection. Serum was purified according to the method described by Mabit et al (4). Specifically, $30 \%$ sucrose was added into serum and then ultracentrifuged at $23 \times 10^{4} \mathrm{x} g$ for $18 \mathrm{~h}$. The supernatant was removed and the precipitation was dissolved in 1X TNE solution. Fluorescent quantitative PCR showed that there were $\sim 5 \times 10^{7}$ copies $/ \mathrm{ml}$ of HBV DNA.

Morphological observation. The morphological change and adhesion of the cells were observed under an inverted phase-contrast microscope every $24 \mathrm{~h}$ after culture.

ELISA. HBsAg and HBeAg in supernatants were detected by the ELISA method according to the manufacturer's instructions (Shanghai Kehua Bio-Engineering, Co., Ltd., Shanghai, China).

Immunohistochemistry. $\mathrm{HBcAg}$ in nuclei was detected by immunohistochemistry according to the manufacturer's instructions (Fuzhou Maixin Biotechnology Development, Co., Ltd., Fuzhou, China).
Table I. HBV DNA in cells and supernatants by fluorescent quantitative PCR.

\begin{tabular}{ccc}
\hline Infection day & $\begin{array}{c}\text { HBV DNA } \\
\text { (non-coated cells) }\end{array}$ & $\begin{array}{c}\text { HBV DNA } \\
(\text { coated cells })\end{array}$ \\
\hline 1 & $4.231 \times 10^{4}$ & $4.231 \times 10^{5}$ \\
2 & 0 & $5.612 \times 10^{4}$ \\
3 & 0 & $7.568 \times 10^{5}$ \\
4 & $3.459 \times 10^{3}$ & $3.523 \times 10^{5}$ \\
5 & $2.312 \times 10^{4}$ & $4.875 \times 10^{5}$ \\
6 & $7.117 \times 10^{4}$ & $7.431 \times 10^{4}$ \\
7 & $1.983 \times 10^{4}$ & $1.566 \times 10^{5}$ \\
8 & $6.233 \times 10^{3}$ & $5.421 \times 10^{4}$ \\
9 & $1.573 \times 10^{3}$ & $1.573 \times 10^{3}$ \\
10 & 0 & $2.135 \times 10^{3}$ \\
\hline
\end{tabular}

HBV, hepatitis B virus.

PCR. The extraction of HBV DNA in cells occurred by digestion with proteinase $\mathrm{K}$, followed by extraction by phenol, chloroform and isoamyl alcohol and ethanol precipitation. Fluorescent quantitative PCR was adopted for the detection of HBV DNA. The forward primer was 5'-TGTGTCTGCGGC GTTTTATC-3' (378-397, $20 \mathrm{bp}$ ) and the reverse primer was 5'-GTTTAAATGTATACCCAGAGAC-3' (816-837, 22 bp). The length of PCR products was $460 \mathrm{bp}$. The amplification conditions were as follows: 35 cycles of $95^{\circ} \mathrm{C}$ for $45 \mathrm{sec}, 54^{\circ} \mathrm{C}$ for $40 \mathrm{sec}$ and $72^{\circ} \mathrm{C}$ for $1 \mathrm{~min}$, followed by a final extension at $72^{\circ} \mathrm{C}$ for $5 \mathrm{~min}$.

HBV cccDNA was detected by nested PCR (5), in which the outer primers crossed over HBV genomic nicks. The outer forward primer of cccDNA was 5'-CCTCTGC CGATCCATCTGCGGAAC-3' (1255-1279, $25 \mathrm{bp})$ and the outer reverse primer was 5'-CTGCGAGGCGAGGGAGTTC TTCTTC-3' (2376-2400, $25 \mathrm{bp}$ ). The length of PCR products was $1139 \mathrm{bp}$. The amplification conditions were as follows: 35 cycles of $95^{\circ} \mathrm{C}$ for $40 \mathrm{sec}$ and $72^{\circ} \mathrm{C}$ for $3 \mathrm{~min}$, followed by a final extension at $72^{\circ} \mathrm{C}$ for $5 \mathrm{~min}$.

The inner positive primer of cccDNA was 5'-CTGAAT CCCGCGGACGACCC-3' (1441-1460, 21 bp) and the inner negative primer was 5'-ACCCAAGGCACAGCTTGGAGG-3' (1867-1889, $23 \mathrm{bp}$ ). The length of PCR products was $449 \mathrm{bp}$. The amplification conditions were as follows: 35 cycles of $95^{\circ} \mathrm{C}$ for $40 \mathrm{sec}, 67^{\circ} \mathrm{C}$ for $40 \mathrm{sec}$ and $72^{\circ} \mathrm{C}$ for $1 \mathrm{~min}$, followed by a final extension at $72^{\circ} \mathrm{C}$ for $5 \mathrm{~min}$.

As mung bean nuclenase (MBN) at a low concentration was sensitive to single-stranded DNA, while insensitive to double-stranded DNA, it was applied in the identification of cccDNA. Cells without infected serum were used as a negative control, while HepG2.2.15 cells were used as a positive control.

\section{Results}

Dynamic morphological changes. Cells inoculated onto non-coated dishes grew well, showing a larger cell volume, 

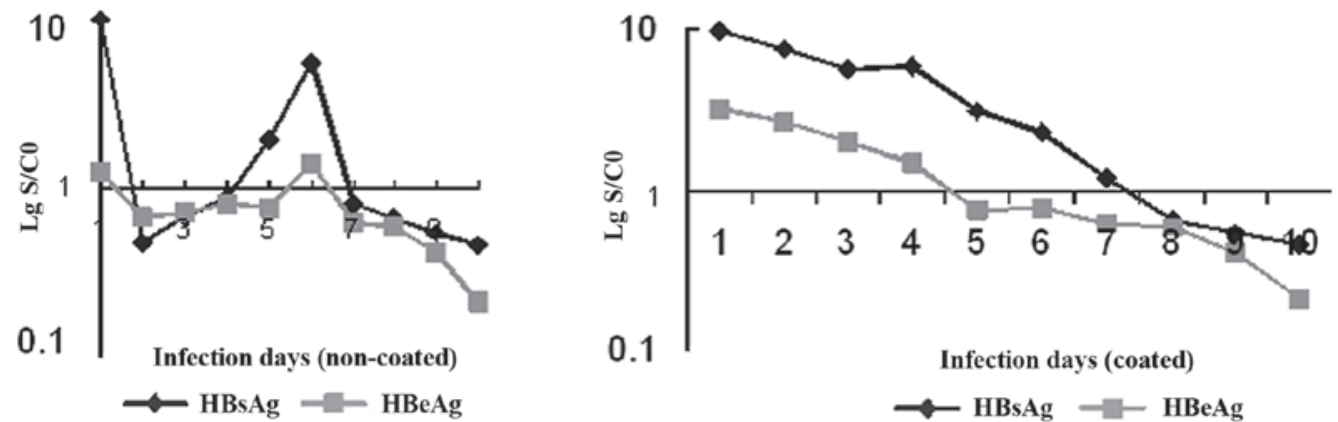

Figure 1. Detection of HBsAg and HBeAg in the non-coated and coated cells by ELISA.

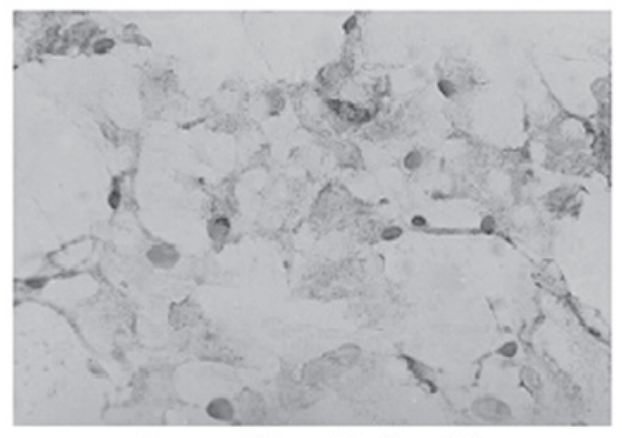

Non-coated; magnification, $\mathrm{x} 200$

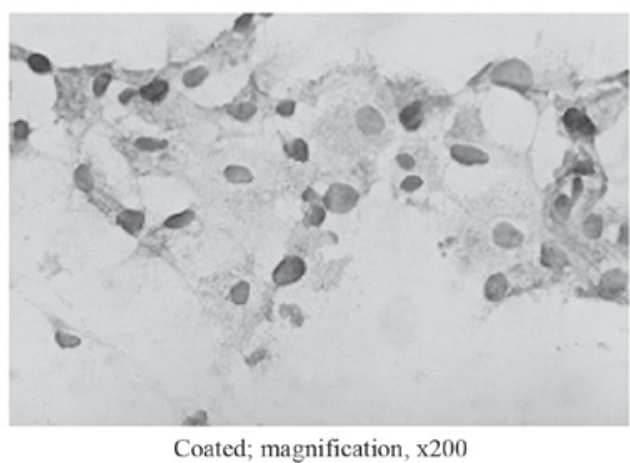

Coated; magnification, $\mathrm{x} 200$

Figure 2. HBcAg in nuclei detected by immunohistochemistry 2 days after infection.

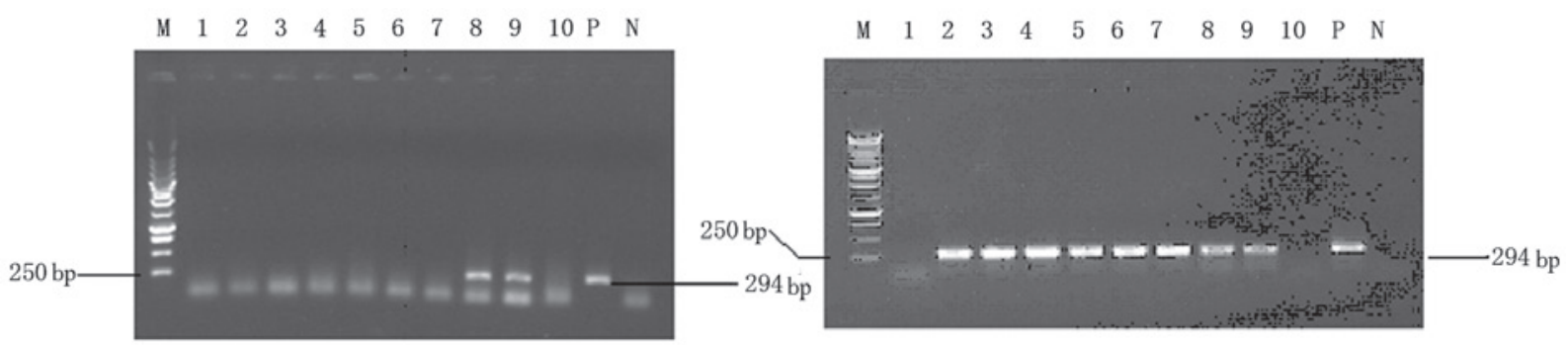

Figure 3. HBV cccDNA in infected cells detected by nested PCR. M, marker; 1-10, infection days; P, positive control; N, negative control; 294 bp, cccDNA. HBV, hepatitis B virus; cccDNA, covalently closed circular DNA.

clear nuclei, active cell proliferation, and were thin and flat irregular polygons in shape. Most of the cells maintained their normal morphological structure within 15 days of culture, with the exception of some that began to lose their normal morphology from day 7 or 8 . After culture (15 days), the majority of the cells died and were replaced by other heterogeneous cells, which grew excessively.

Compared to the cells on the non-coated dishes $6 \mathrm{~h}$ after inoculation, cells on the coated dishes displayed stronger adhesion and adherence abilities, a more spreading shape, a larger cell volume, more granules in the cytoplasm, earlier apoptosis and a shorter time span to maintain their normal morphology. Twelve days later, almost all the cells had lost their normal morphology.

Replication and expression of $H B V$ in hepatocytes. Fluorescent quantitative PCR showed that the solution kept from the sixth wash after the inoculation of positive HBV DNA from serum was negative for HBV DNA. Detection of the series of stored supernatants following HBV infection by ELISA showed that HBsAg and HBeAg in the non-coated cells were positive on day 1 , were negative from day 2 with a subsequent increase in the HBsAg signal-to-cutoff $(\mathrm{S} / \mathrm{CO})$ value, reappeared positive on day 5-6, and then became negative once again with a decrease of the $\mathrm{S} / \mathrm{CO}$ value; HBsAg in the coated cells was found to be positive on day 1 and became negative until day 7; but $\mathrm{HBeAg}$ in the coated cells displayed the same variation compared to the non-coated cells (Fig. 1). Immunohistochemical detection showed that $\mathrm{HBcAg}$ in the nuclei of the non-coated cells was positive from day 2 with a positive rate of $\geq 15 \%$, and the nuclei and part of the cytoplasm and intercellular substance were stained; $\mathrm{HBcAg}$ in the nuclei of the coated cell was found to be positive from day 1 with a positive rate of $>90 \%$ and the majority of the staining 
occurred in the nuclei. In addition, with the prolongation of infection time, the number of infected cells did not increase in any of the groups (Fig. 2). Fluorescent quantitative PCR showed that HBV DNA in the non-coated cells was detected from day 5 , and the copy number increased from then on and began to decrease from day 9; HBV DNA in the coated cells was detected from day 1 with a higher titer compared to the non-coated cells, and the copy number began to drop gradually one week later (Table I).

Nested PCR showed that HBV cccDNA in the non-coated cells appeared from day 8 and the results were negative from day 10 ; HBV cccDNA in the coated cells was positively detected from day 2 and turned negative from day 9. The detection of cccDNA was not influenced by the action of MBN on the templates (Fig. 3).

\section{Discussion}

FN is distributed among all the extracellular spaces in the liver, including the blood sinusoids and the basilar membranes. Hepatocytes, hepatic endotheliocytes, Ito cells and Kupffer cells are all capable of synthesizing FN. According to its different distribution areas, FN may be divided into cellular and plasmic FN. Cellular FN exists in the extracellular matrix in an insoluble form, while plasmic FN exists in the blood plasma in a soluble form (1). FN is a protein that possesses multiple biological functions. According to the literature, FN in the blood sinusoids in the human liver may promote the uptake of HBV by hepatocytes (2). However, to date, the molecular mechanism of HBV infection in human hepatocytes remains unknown. Thus, in this study, the effect of FN on human fetal hepatocytes infected by HBV was investigated, with the aim of further elucidating the mechanism of HBV infection in hepatocytes.

FN may be expressed in tissue culture cells of healthy individuals and rats, whereas it will decrease or even disappear on the surface of cells in which there is some transformation, or on the surface of induced or spontaneous tumor cells. FN has the following effects on cultured cells: i) The adhesive attraction effect. FN is capable of promoting the mutual adhesion ability between cells and the adherence ability between cells and supporting materials $(6,7)$. The mechanisms underlying its adhesive attraction remain unclear. Presumably, one mechanism may be that specific gangliosides or related sialoglycoconjugates are the receptors of FN on the surface of cells, and another may be that FN is an extensible biomacromolecule that binds with plastics, collagens, gelatins, fibers and proteoglycans. ii) The effects on cell growth, proliferation and differentiation. Bitterman et al discovered that FN could promote the proliferation of human diploid fibroblasts (8). A study on the effect of FN in a rat liver cell line showed that normal hepatocytes could not grow in medium without serum, but those after transformation could grow, indicating that those transformants could synthesize FN for their own growth requirements (9). Studies on FN receptors on the cell surface also indicate that there is a correlation between $\mathrm{FN}$ and cell growth. Spiegelman and Ginty (10) proved that FN inhibited the differentiation of $3 \mathrm{~T} 3$ adipose cells. The mechanism underlying the promotion effect of FN on cell growth and proliferation may be associated with the direct influence of
FN on cells or with the method by which FN activates target cells to produce more growth factors. The mechanism of the inhibitory effect of FN on cell differentiation may be correlated with the influence of FN on cytoskeletons. iii) The effect on morphological changes of cells. It has been proven that FN may lead to morphological changes of fibroblasts. The added purified FN in the culture system could make transformed fibroblasts appear more spread and flatter in morphology (such as normal cells), and such an effect could also be found when it was added to the alveolar epithelial cell line and the breast cancer cell line (11). iv) The migration and diffusion effects. The content of FN is directly proportional to the migration and diffusion of cells. v) The invasion and metastasis effects. FN may inhibit the invasion and metastasis of tumor cells.

In this study, the results revealed that cells coated with FN, compared to those not coated, displayed stronger adhesion and adherence abilities, a more spreading appearance, a larger cell volume and a faster cell proliferation rate, which is consistent with reports in the related literature. In addition, our results showed that the granules in the cytoplasm increased, the time of cell death was advanced and the time span for normal morphological maintenance was shortened. The possible reason may be that $\mathrm{FN}$ is capable of speeding up cell proliferation at the early stage of cell culture. When cells proliferate to a certain degree, proliferation begins to slow down and finally stops due to the contact inhibition characteristics of cells. After some time of maintenance, cells begin to die and shed off.

This study also found that FN coating advanced HBV infection and increased the number of infected cells. The hepatocytes coated with FN were infected with serum with HBV after $24 \mathrm{~h}$ of culture and detected by ELISA. Results showed that HBsAg was positive from day 1 and the titer began to decrease gradually after 7 days, while positive HBsAg in the non-coated cells could only be detected on day 5 or 6 . Immunohistochemistry results showed that $\mathrm{HBcAg}$ in the coated cells appeared positive from day 1 after infection with a positive rate of $>90 \%$, while $\mathrm{HBcAg}$ in the non-coated cells appeared positive from day 2 after infection, with a positive rate of $15 \%$. Results by fluorescent quantitative PCR showed that HBV DNA in the coated cells was detected from day 1 , the copy number was maintained at a high level and the high level began to gradually drop one week later, while HBV DNA in non-coated cells was detected from day 5 with a relatively low copy number. Results by nested PCR showed that cccDNA in the coated cells appeared positive from day 2 and was negative from day 10 , while in the non-coated cells cccDNA appeared positive from day 8 and was negative two days later. Our results showed that the infectivity of the cells disappeared with the prolongation of infection time, which may be a result of the cells dying in the late stage of culture and a decrease in the number of infected cells. The infection time of the coated cells was not prolonged compared to that of the non-coated cells, which may be correlated with the advanced time of cell death and the shortened cell survival time. Among the different methods adopted in this study, immunohistochemistry was the method able to detect HBV infection the earliest, showing a high sensitivity. Mung bean nuclease was used for the identification of cccDNA in this study, displaying good specificity. 
A possible mechanism underlying the promoting effect of FN on HBV infection in hepatocytes may be that FN improves cell-cell and cell-supporting material adhesion and adherence abilities, and promotes cell growth and proliferation, which is of great help for HBV infection. Another possible mechanism may be that FN mediates HBV infection of hepatocytes directly. According to Budkowska et al (2), FN in human hepatic blood sinusoids could bind with HBV via antigenic determinants coded by the HBV S2 area, and such binding could accelerate the uptake of HBV by hepatocytes, while recombinant $\mathrm{HBsAg}$ granules could not bind with $\mathrm{FN}$ in the liver due to lack of antigenic determinants coded by the HBV $\mathrm{S} 2$ area. It is very possible that $\mathrm{FN}$ has the same effect in vitro to accelerate HBV infection in fetal hepatocytes. However, further studies are still required for confirmation.

\section{References}

1. Kornblihtt AR, Pesce CG, Alonso CR, et al: The fibronectin genes as a model for splicing and transcription studies. FASEB J 10: 248-257, 1996.

2. Budkowska A, Bedossa P, Groh F, Louise A and Pillot J: Fibronectin of human liver sinusoids binds hepatitis B virus: identification by an anti-idiotypic antibody bearing the internal image of the pre-S2 domain. J Virol 69: 840-848, 1995.
3. Wang YM, Chen GZ, Dong JH, Yuan LP, Liu GD and Ding J: An in vitro perfusion method for the isolation of hepatocytes. Chin J Dig 14: 175-178, 1994 (In Chinese).

4. Mabit H, Dubanchet S, Capel F, Dauguet C and Petit MA: In vitro infection of human hepatoma cells (HepG2) with hepatitis B virus (HBV): spontaneous selection of a stable HBV surface antigen-producing HepG2 cell line containing intergrated HBV DNA sequences. J Gen Virol 75: 2681-2689, 1994.

5. Lu X, Block TM and Gerlich WH: Protease-induced infectivity of hepatitis B virus for a human hepatoblastoma cell line. J Virol 70: 2277-2285, 1996.

6. Hynes RO and Yamada KM: Fibronectins: Multilfunctional modular glycoproteins. J Cell Biol 95: 369-377, 1982.

7. D'Ardenne AJ and Barnard NJ: Paucity of fibronectin in invasive lobular carcinama of breast. J Pathol 157: 219-224, 1989.

8. Bitterman PB, Rennard SI, Adelberg S and Crystal RG: Role of fibronectin as a growth factor for fibroblasts. J Cell Biol 97: 1925-1932, 1983.

9. Junker JL and Heine UI: Effect of adhesion factors fibronectin, laminin, and type IV collagen on spreading and growth of transformed and control rat liver epithelial cells. Cancer Res 47: 3802-3807, 1987.

10. Spiegelman BM and Ginty CA: Fibronectin modulation of cell shape and lipogenie gene expression in 3T3-adipocytes. Cell 35: 657-666, 1983.

11. Steele JG, Savolainen TA and Smith GJ: Expression of fibronectin on clonally related transformed and control sublines from an epithelial cell strain and a tumor line of mouse alveolus. Cancer Res 48: 4933-4940, 1988. 